\title{
Lumbar and Abdominal Muscles Isometric Potential in Volleyball Cadets
}

\author{
Potencial Isometrico de Músculos Lumbares y Abdominales en Cadetes de Voleibol
}

\begin{abstract}
Zoran Bogdanovic*; Miroslav Smajic**; Damjan Jaksic**; Zoran Milosevic**; Borislav Obradovic**; Aleksandra Gogic***; Hadzi Milos Vidakovic"; Milija Ljubisavljevic****; Vesko Draskovic ${ }^{* * * * * *}$; Svetlana Visnjic ${ }^{* * * * * * *}$; Hasim Mekic*; Ratko Stankovic ${ }^{* * * * * * * * *}$; Goran Ivancic (********** \& Stevo Popovic $^{* *}$
\end{abstract}

BOGDANOVIC, Z.; SMAJIC, M.; JAKSIC, D.; MILOSEVIC, Z.; OBRADOVIC, B.; GOGIC, A.; VIDAKOVIC, H. M.; LJUBISAVLJEVIC, M.; DRASKOVIC, V.; VISNJIC, S.; MEKIC, H.; STANKOVIC, R.; IVANCIC, G. \& POPOVIC, S. Lumbar and abdominal muscles isometric potential in volleyball cadets. Int. J. Morphol., 32(3):1036-1042, 2014.

SUMMARY: Given that a volleyball game requires a certain level of individual anthropological characteristics of young volleyball players to successfully act on situational conditions, and that interdisciplinary approach in the science study is the principal methodological orientation, subject of study in the field of sports is the anthropological status. The aim of this study was to analyze the possible differences in spinal lumbar and abdominal muscles isometric potential of prospective male and female. Sample included 42 subjects (15 male and 27 female subjects), male and female volleyball players, the cadet selection of Serbia, aged $14 \pm 0.5$ years. Isometric muscle potential assessment was conducted using four standardized motor movement tasks, covering the following areas: static contraction of the flexors of the torso, static contraction of the extensors of the torso, static contraction of the left flexor of the torso, and static contraction of the right flexor of the torso. In addition to the descriptive statistics used, as basis statistics, the t-test for independent samples was used, to compare the mean values of parameters measured in two different groups of athletes - volleyball players (girls - boys). Descriptive indicators of the sample suggest greater values of deep spinal muscles isometric potential with boys in all study variables. Study results gained by the t-test of independent samples indicate that statistically significant difference exists between their mean results in variables of trunk flexor static contractions and trunk extensor static contractions, at the level 0.001. With other two variables, the values indicate that difference between genders is not significant but accidental. The results of this study regarding static contraction of the right and left lateral flexors of the torso show the lack of statistical significance between male and female cadet volleyball players.

KEY WORDS: Muscle Strength; Trunk; Volleyball Players.

\section{INTRODUCTION}

Structure of motor requests which are characteristic for a volleyball game, consists of frequent changes of direction, numerous jumps, spike jumps etc. (Hadzic et al., 2012). The above-mentioned characteristics require adequate preparation and high performance in terms of sporting techniques and specific physical preparation (Micoogulları et al., 2012). On the other hand, in the area of motor movement there are three basic forms of muscle strain expression, i.e. manifestation of muscular energy (potential): isometric muscle potential, ballistic muscle potential and repetitive muscle potential. Isometric muscle potential is expressed through the static mode that is reflected in the ability of enduring and maximum maintaining of the muscle strength (Akpinar et al., 2012) while there is no movement and muscle belly approximation. Typical motor activities for this mode of expressing the strength are various endurance, balance, standstill, holding movement or great load positions. Mechanisms of strength manifestation,

State University of Novi Pazar, Department of Biomedical Sciences, Novi Pazar, Serbia.

** University of Novi Sad, Faculty of Sport and Physical Education, Novi Sad, Serbia.

**** Military Medical Academy, Institute for Scientific Information, Belgrade, Serbia.

***** Ministry of Interior, Internal Affairs Sector, Novi Beograd, Serbia.

***** $\quad$ Alfa University, Faculty of Sports Management, Belgrade, Serbia.

****** Center for Sports, Recreation and Physical Education "Studio No1", Belgrade, Serbia.

******** University of Nis, Faculty of Sport and Physical Education, Nis, Serbia.

********** Futsal Club "Tvdrava", Novi Sad, Serbia.

University of Montenegro, Faculty for Sport and Physical Education, Niksic, Montenegro. 
BOGDANOVIC, Z.; SMAJIC, M.; JAKSIC, D.; MILOSEVIC, Z.; OBRADOVIC, B.; GOGIC, A.; VIDAKOVIC, H. M.; LJUBISAVLJEVIC, M.; DRASKOVIC, V.; VISNJIC, S.; MEKIC, H.; STANKOVIC, R.; IVANCIC, G. \& POPOVIC, S. Lumbar and abdominal muscles isometric potential in volleyball cadets. Int. J. Morphol., 32(3):1036-1042, 2014.

especially isometric muscle potential, are primarily related to morpho-functional characteristics of the muscle: the mass of employed muscles, the size of their cross-sections, the structure of their fibres at the muscle cell excitation, impulse transfer speed through the synapse etc. as well as biochemical and metabolic processes in the employed muscle and the presence of energy resources in them (Stojiljkovic, 2003). This type of muscle potential is present during static posture of the body or any part of it. When talking about this, it is thought in the first place of, the postural muscles that are responsible for the proper functioning of the locomotor system as well as other parts of the body, especially the lumbar and abdominal regions. With postural muscles of the back, red (slow-twitch) muscle fibres dominate. Diameter of the muscle fibres is slightly smaller, with smaller sarkoplasm but with greater efficiency for oxygen, which allows them to work longer without fatigue (Bjelica et al., 2013). These muscles mainly work under anaerobic conditions. There is an assumption that the endurance of postural muscles is directly related to the density of red muscle fibres in the lumbar region and that the lack of static strength and ability to resist fatigue is a risk factor for the occurrence of various changes in that part of the spinal column. However, this assumption is presumably still in the research domain (Bogduk, 2005).

During the process of growth and development, the spinal column is one of the points of the locomotor system that is sensitive to the effects of external factors, and there are frequent cases of power reduction of abdominal and back muscles. Data on anthropometric characteristics and the endurance of the muscles of the lower back and abdomen are the subject of many studies that dealt with the influence of certain factors (Balagué et al., 1995; Salminen et al., 1993), external factors (Viry et al., 1999; Watson et al., 2002; Balagué et al., 1999), as well as the status of the spinal cord (Dejanovic \& Zivkovic, 2008). The general consensus is that a statistically significant correlation has been noticed between anthropometric characteristics and isometric endurance of the lumbar and abdominal muscles in the studied population (Dejanovic \& Zivkovic). There is much scientific and empirical evidence supporting the claim that there are differences between the body size of athletes in various sports and games and the events within the same sport. Age, height and body size of the athletes at national and international level are significant from several aspects, and significant linear connection between back muscles strength and body height of the subjects was determined (Mannion et al., 1999). Height, weight and other anthropometric characteristics are essential for success in certain sports (Bjelica et al., 2012). In some sports, less height and weight are necessary to achieve maximum results, while in others higher height and weight are necessary for excellent results (Popovic et al., 2013a). For success in basketball, height is of great importance (Popovic et al., 2013b). Volleyball players need to be high with well developed muscles, for they must show the required physical properties of the rally (Parizkova, 1991; Maffulli, 1992). Football players have been determined to belong to a group in which morphological characteristics show considerable variability, so the logical conclusion is that the previously mentioned characteristics are not of great importance for success (Hadzic et al.). In the area of mobility, it was determined that football players are characterized by high frequency and speed of movement as well as by a high level of coordination. By determining differences in morphological space of the above mentioned sports games athletes there is given data that statistically significant differences between selected football and volleyball players exist in measured morphological characteristics (Nejic et al., 2009).

Given that a volleyball game requires a certain level of individual anthropological characteristics of young volleyball players to successfully act on situational conditions, and that interdisciplinary approach in the science study is the principal methodological orientation, subject of study in the field of sports is the anthropological status. As there are specificities of certain sports that originate from differences in their competitive structure, so there is a constant need for continuing theoretical research and practical testing of these specificities. In volleyball it means testing of some anthropological abilities and characteristics. The idea of this research is to be the test of what the current practice has shown, that is, when it comes to male and female players, that to a greater or lesser degree, there are some differences in body size and specific motor abilities, and that the efficiency of test realization is indirectly and directly affected by many factors, not only from the motor area, but the area of complete anthropological status of volleyball player. Therefore, the aim of this study was to determine possible differences between isometric potential of lumbar and abdominal regions of the spinal column with the cadet male and female volleyball selection of Serbia.

\section{MATERIAL AND METHOD}

The research of transversal character has been conducted on the representative sample of prospective male and female volleyball players of the cadet selection at the level of entire Serbia, of age $14 \pm 0.5$ years. Cadet selection of Serbia was conducted by Trainer organisation as part of Volleyball Federation of Serbia. Sample of subjects included 42 (15 male and 27 female subjects), and all participants gave their consent in writing after they had been informed 
BOGDANOVIC, Z.; SMAJIC, M.; JAKSIC, D.; MILOSEVIC, Z.; OBRADOVIC, B.; GOGIC, A.; VIDAKOVIC, H. M.; LJUBISAVLJEVIC, M.; DRASKOVIC, V.; VISNJIC, S.; MEKIC, H.; STANKOVIC, R.; IVANCIC, G. \& POPOVIC, S. Lumbar and abdominal muscles isometric potential in volleyball cadets. Int. J. Morphol., 32(3):1036-1042, 2014.

on the testing protocol. Isometric muscle potential assessment was conducted using four standardized motor movement tasks, covering the following areas: static contraction of the flexors of the torso, static contraction of the extensors of the torso, static contraction of the left flexor of the torso, and static contraction of the right flexor of the torso (McGill et al., 1999). Out of the anthropometric parameters, body height and weight were used, and the measurement carried out in accordance with the guidelines of the International Biological Programme (Weiner \& Lourie, 1969). Instruments were of standard production and calibrated before measuring.

The tests for assessing isometric strength of the flexor, lateral flexor and extensor forces of the participants were carried out in the prone position on the side, with the participant lying on their forearm (the lateral flexors), lying down on the stomach with the body outside the area of support (the extension of torso) and seated position and the angle between the torso and thigh of 90 degrees, and the angle between the leg and thigh of 90 degrees (McGill et al.).

All subjects gave written consent after the notification of the test protocol. Study protocol was approved by the Ethics Committee of the Faculty of Sport and Physical Education, University of Nis, according to the revised Declaration of Helsinki. Participants were tested by the author of this work in the sports hall. During the test, the air temperature ranged from $22^{\circ} \mathrm{C}$ to $25^{\circ} \mathrm{C}$. Testing began at 10 am and finished until $13 \mathrm{pm}$. Standard anthropometry (height, body weight), are the tests that were carried out first, and the players were instructed on how to conduct further testing of muscle groups. The tests that isolate these muscle groups are very difficult to construct, but the next group of tests represents the best solution. The fact that each has a statistic significant of 0.98 speaks in favour of it (McGill et $a l$.). One muscle group per day is being tested, or one test per day, so subject would be rested and results more valid and objective. Before testing is carried subjects primarily applied the warming protocol in duration up to 15 minutes, as the authors McGill et al. proposed in order to activate the muscles, and to obtain more valid and objective results and prevent possible injury to muscle. Each subject performed a standard 15-minute warm-up consisting of general movements and the dynamic and static stretching.

Test of static left and right torso lateral flexor muscle endurance-variables (M. obliquus externus et interims abdominis, M. quadratus lumborum): Subject takes the prone position leaning on the side of the forearm. The legs are stretched in a slight step forward position, so that the upper leg is positioned slightly forward. The body needs to be stretched without any sort of bending. The other, free arm is positioned on the opposite shoulder. We stop the time when proper posture is distorted, i.e. when subject touches the ground with hand. Time is measured in seconds with an accuracy of $0.10 \mathrm{sec}$.

Test of static torso flexor muscle (M. rectus abdominis, M. psoas, M. illiacus): Subject is leaned back on the bench that is angled at 50 degrees to the plane. One of the measuring assistants fixes the subject's feet on the ground so that the knees are angled at 90 degrees to the ground. Subject fixes its hands to the chest, crossed. The other assistant holds the bench and in agreement with the third one who measures time he/she slips the bench $10 \mathrm{~cm}$ away from the subject's back. We stop the time when proper posture is distorted, i.e. when subject touches the bench with any part of his body. Time is measured in seconds with an accuracy of $0.10 \mathrm{sec}$.

Test of statical torso extensor muscle endurance ( $M$. erector spinae): Subject takes the position on a bench or the Swedish box, relying on his hips and legs that were fixed by second measuring assistant. The arms are fixed on the chest, crossed, hands touching the shoulders. We stop the time when proper posture is distorted, i.e. when subject is no longer able to hold the horizontal position. Time is measured in seconds with an accuracy of $0.10 \mathrm{sec}$.

For statistical analysis the Statistical Package for the Social Sciences SPSS was used (version 20.0, SPSS Inc., Chicago, IL), in order to achieve clear interpretation of the obtained results. In accordance with set aim, the basic descriptive statistics was used. t-test for independent samples is used for comparison of mean values of the measured characteristics of two different groups of volleyball players (girls - boys). Finally, these differences were plotted as bar diagrams with help of "R" statistic software, open source stat program.

\section{RESULTS}

All results are presented in Table I, as well as in Figure 1. According to the mean in all measures and tests for the assessment of spinal lumbar and abdominal region isometric potential, we can state the following: differences between volleyball players according to sex are significant in Body height $(181.87 \mathrm{~cm}$ in boys compared to $176.78 \mathrm{~cm}$ in girls, $\mathrm{p}=0.01)$, as well as in body weight $(70.53 \mathrm{~kg}$ in boys vs. $54.81 \mathrm{~kg}$ in girls, $\mathrm{p}=0.00$ ).

If we take a look on results on other four variables, it could be concluded that girl volleyball players have higher results in all variables compared with boys. But all 
BOGDANOVIC, Z.; SMAJIC, M.; JAKSIC, D.; MILOSEVIC, Z.; OBRADOVIC, B.; GOGIC, A.; VIDAKOVIC, H. M.; LJUBISAVLJEVIC, M.; DRASKOVIC, V.; VISNJIC, S.; MEKIC, H.; STANKOVIC, R.; IVANCIC, G. \& POPOVIC, S. Lumbar and abdominal muscles isometric potential in volleyball cadets. Int. J. Morphol., 32(3):1036-1042, 2014.

differences are not statistically significant. The significant differences are in Static contraction of the left flexor of the torso and Static contraction of the flexors of the torso, in both cases on $\mathrm{p}$ level lower than 0.05 . In the other two va-
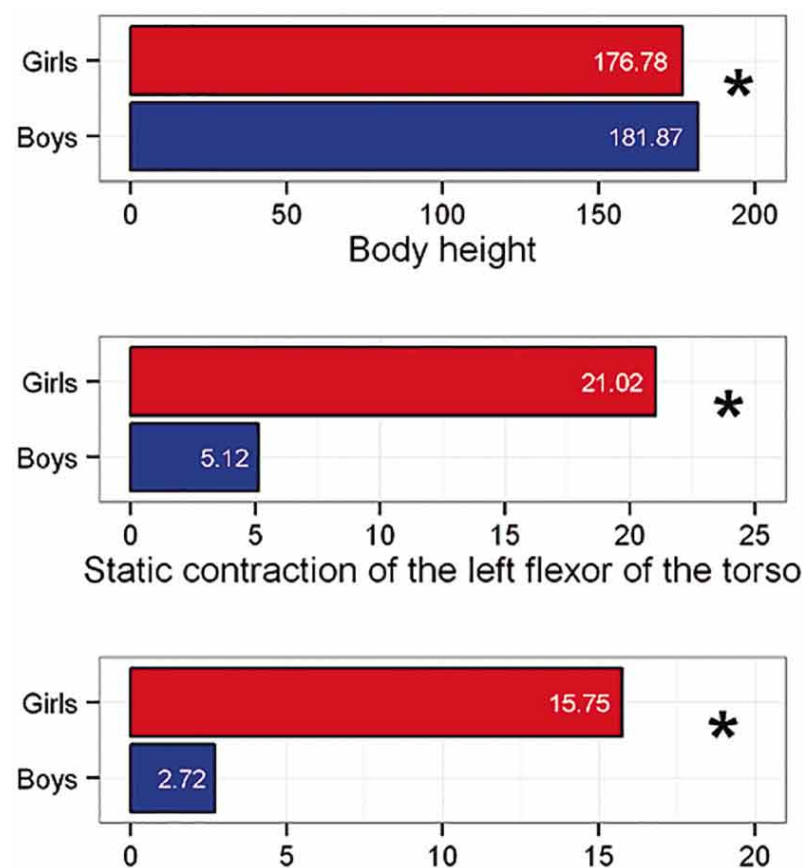

Static contraction of the flexors of the torso riables, i.e. Static contraction of the right flexor of the torso and Static contraction of the extensors of the torso there was not significant differences between boys and girls.
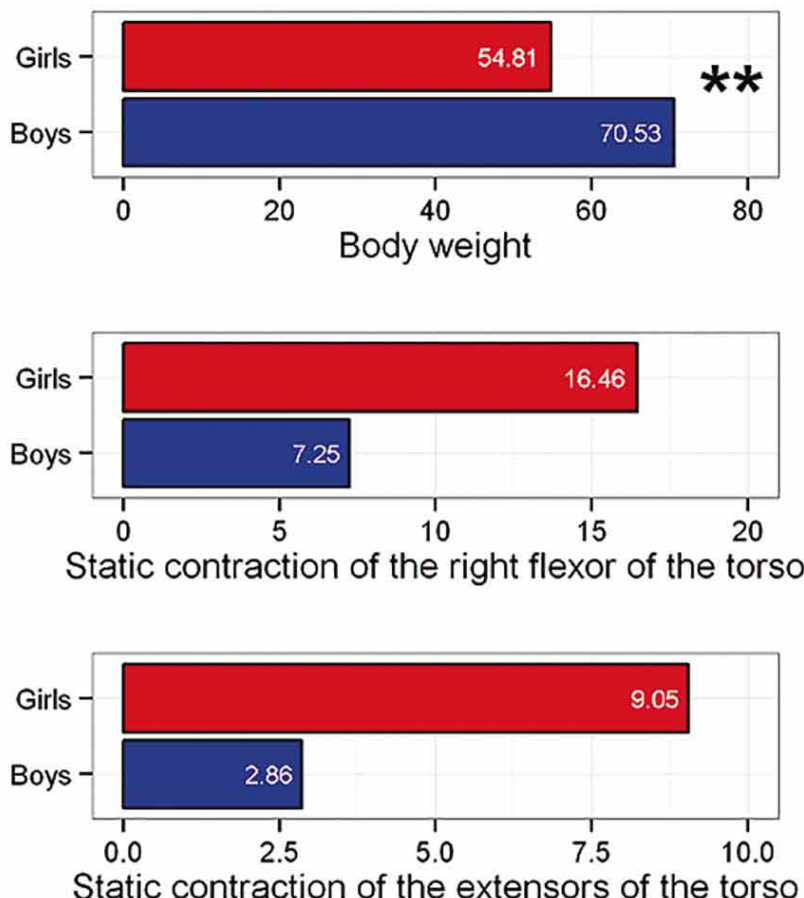

Fig. 1. Differences between players. Legend: $* *=$ significance $\leq 0.01$; * significance $\leq 0.05$.

Table I. Differences between boys and girls volleyball players.

\begin{tabular}{lcccccc}
\hline \multicolumn{1}{c}{ Variable } & \multicolumn{2}{c}{ Boys $(\mathbf{n}=\mathbf{1 5})$} & \multicolumn{2}{c}{ Girls $(\mathbf{n = 2 7})$} & \multirow{2}{*}{ t } & \multirow{2}{*}{$\mathbf{p}$} \\
\cline { 2 - 5 } & Mean & SD & Mean & SD & & \\
\hline Body height $(\mathrm{cm})$ & 181.87 & 6.74 & 176.78 & 5.83 & 2.56 & 0.01 \\
Body weight $(\mathrm{kg})$ & 70.53 & 5.38 & 54.81 & 5.41 & 9.03 & 0.00 \\
Static contraction of the left flex or of the torso & 5.12 & 14.36 & 21.02 & 23.01 & -2.75 & 0.01 \\
Static contraction of the right flex or of the torso & 7.25 & 15.96 & 16.46 & 21.62 & -1.57 & 0.12 \\
Static contraction of the flex ors of the torso & 2.72 & 0.91 & 15.75 & 23.62 & -2.86 & 0.01 \\
Static contraction of the extensors of the torso & 2.86 & 0.72 & 9.05 & 17.20 & -1.87 & 0.07 \\
\hline
\end{tabular}

\section{DISCUSSION}

Based on the previous analysis, we can conclude that male players are stronger, heavier, have more height, better speed and agility than female players. Other authors also point to these and similar research results. Isometric endurance of the lumbar and abdominal muscles results shows a few statistically significant multiple correlations between anthropometric characteristics and durability of the lumbar extensors. The multiple correlations of anthropometric characteristics and abdominal muscle endurance were not statistically significant (Zivkovic \&
Dejanovic, 2008). The research results obtained on 98 cricket players from various universities in India may be given. They suggest that the strength of the back has a positive correlation with the strength of the legs, but not with other anthropometric characteristics. The results differ from most research dealing with relations between anthropometric characteristics and body deep spinal muscles isometric endurance (Koley et al., 2010). Nikolaidis et al. (2012), by means of data analysis, point out three main discoveries. 
BOGDANOVIC, Z.; SMAJIC, M.; JAKSIC, D.; MILOSEVIC, Z.; OBRADOVIC, B.; GOGIC, A.; VIDAKOVIC, H. M.; LJUBISAVLJEVIC, M.; DRASKOVIC, V.; VISNJIC, S.; MEKIC, H.; STANKOVIC, R.; IVANCIC, G. \& POPOVIC, S. Lumbar and abdominal muscles isometric potential in volleyball cadets. Int. J. Morphol., 32(3):1036-1042, 2014.

They indicate existence of differences in physical physiological characteristics between three age categories of adolescents and senior Greece volleyball female players. Participants were divided into 3 age groups - younger than $14,14-18$, as well as over 18 . Authors point to the great need for the trainer to use this information in designing training, strength and conditioning program.

The aim of another study was to test the reliability of parameters and characteriscs of muscle strength with both sexes. Fifteen males and fifteen females paticipated in this study. Authors conluded that maximum strength for men is higher than for women for all applied load (Demura \& Miiaguchi, 2009). Noyes et al. (2011) determined whether specific training can lead to improvements in neuromuscular indices in thirty-four high school volleyball players aged $14.5 \pm 1.0$ years. The authors concluded that the implemented program significantly improved the strength of the lower extremities, vertical jumping ability and abdominal strength. They also suggested that such program can be implemented at the high school volleyball player population. On testing the physiological and anthropometric characteristics of the one hundred fifty-three junior volleyball players who compete in the elite, semi-elite and novice levels, it was determined that male players were taller, heavier, leaner, and had more height, better speed, agility, and muscle strength than female players. These results provide data and include standards for junior volleyball players who compete in the elite, semi-elite and novice levels. Given the improvement of muscle strength in the lower extremities, agility and increased level of game, and given the importance of these characteristics in competitive games, trainers should work on these characteristics to improve the very game of young male players (Gabbett \& Georgieff, 2007).

In determining the status and development of motor abilities of pioneers and cadet male population selection of Serbia in the period since 1996 to 2004, on a sample of 353 male players, it was concluded that in this period the generations from 2003 and 2004 had significantly better results in the area of explosive strength. These data clearly indicate that the level of this ability has increased significantly in the period since 1996 to 2004. The assumption behind this increase is that the requests of national teams contributed to better work in the development of explosive strength of the club selections, and more demanding criteria of selection for the national team of Serbia (Stojanovic et al. 2008). The physical abilities and characteristics of adolescent volleyball club were tested at twenty-nine adolescents, of age 12 to 17 . The results indicate that age, experience, body mass, strength and balance are the key to physical abilities and characteristics of adolescent girls who play volleyball. Potentially, this type of information will allow trainers and athletes to identify possibilities specific for age category and evaluation of players in development (Melrose et al., 2007). In the study sample of 40 selection girls, their morphological structure and functional abilities were determined. It can be concluded that, except for height in selection we require high capacity jump and explosive strength not only of the muscles of lower and upper extremities but back muscles as well (MladenovicCiric \& Djuraskovic, 2008).

In order to determine what impact a one-year systematic physical exercise had on the physical fitness, the content of which were sports-volleyball game, the fitness of the students of the Pedagogic Academy in Sombor-Serbia was studied, on the start of the first year in the end of the school year. There were tested: speed, agility, explosive strength, coordination, repetitive forces and the static force. The results showed that the fitness of the students, except speed, influenced by the regular practice, the content of which was volleyball, held at the starting level. On a sample of 50 male and 55 female volleyball players aged fourteen, summer camp participants candidates for the Serbian national team, a study with the aim of comparative analysis of some anthropometric measures and motor abilities was conducted. The results indicate that the differences in all variables are statistically significant in favour of male players, except in variable deep bench bias, where female players had better results (Stojanovic et al., 2005).

The results of this study regarding static contraction of the right and left lateral flexors of the torso show the lack of statistical significance between male and female cadet volleyball players. This leads us to the necessity for greater involvement of the large muscle groups with male volleyball players in relation to female volleyball players and the need for inclusion of these data in the training process, and the work of the trainers to improve these characteristics of volleyball players at the age studied, in order to improve play of individual, team and later, the game.

BOGDANOVIC, Z.; SMAJIC, M.; JAKSIC, D.; MILOSEVIC, Z.; OBRADOVIC, B.; GOGIC, A.; VIDAKOVIC, H. M.; LJUBISAVLJEVIC, M.; DRASKOVIC, V.; VISNJIC, S.; MEKIC, H.; STANKOVIC, R.; IVANCIC, G. \& POPOVIC, S. Potencial isometrico de músculos lumbares y abdominales en cadetes de voleibol. Int. J. Morphol., 32(3):1036-1042, 2014.

RESUMEN: Al considerar que un partido de voléibol requiere cierto nivel de características antropológicas individuales de los jóvenes jugadores de voléibol para actuar con éxito en condiciones situacionales, el enfoque interdisciplinario principal en el estudio de las ciencias del deporte es la orientación metodológica, como también lo es el estado antropológico de los jugadores. El 
BOGDANOVIC, Z.; SMAJIC, M.; JAKSIC, D.; MILOSEVIC, Z.; OBRADOVIC, B.; GOGIC, A.; VIDAKOVIC, H. M.; LJUBISAVLJEVIC, M.; DRASKOVIC, V.; VISNJIC, S.; MEKIC, H.; STANKOVIC, R.; IVANCIC, G. \& POPOVIC, S. Lumbar and abdominal muscles isometric potential in volleyball cadets. Int. J. Morphol., 32(3):1036-1042, 2014.

objetivo de este estudio fue analizar las posibles diferencias en la columna lumbar y el potencial isométrico en los músculos abdominales masculinos y femeninos. En la muestra fueron incluidos 42 sujetos (15 varones y 27 mujeres) jugadores de voléibol masculino y femenino de la selección cadete de Serbia, de $14 \pm 0,5$ años. Se realizó evaluación del potencial muscular utilizando cuatro tareas de movimiento de motor estandarizados en las siguientes áreas: la contracción estática de los flexores del torso, de contracción estática de los extensores del tronco, contracción estática del flexor izquierdo del torso, y la contracción estática del flexor derecho del torso. Además de las estadísticas descriptivas y las estadísticas de base utilizadas, se usó la prueba t para las muestras independientes para comparar los valores medios de los parámetros medidos en dos grupos diferentes de los deportistas jugadores de voléibol (niñas - niños). Los indicadores descriptivos de la muestra sugieren mayores valores de potencial isométrico de los músculos espinales profundos en niños en todas las variables del estudio. Los resultados del estudio obtenidos por la prueba t de muestras independientes indicaron que existe una diferencia estadísticamente significativa entre los resultados medios en las variables de los flexores del tronco y en las contracciones estáticas de los extensores del tronco, en el nivel de 0,001. Con otras dos variables, los valores indicaron que la diferencia entre ambos sexos no es significativa pero es accidental. Los resultados de este estudio con respecto a la contracción estática del lado derecho y flexores laterales izquierdos del torso muestran la falta de significación estadística entre los jugadores masculinos y femeninos de voléibol.

PALABRAS CLAVE: Potencia muscular; Tronco; Jugadores de voleibol.

\section{REFERENCES}

Akpınar, S.; Zileli, R.; S, enyüzlü, E. \& Tunca, S. Predictors affecting the ranking in women armwrestling competition. Monten. J. Sports Sci. Med., 1(1):11-4, 2012.

Balagué, F.; Skovron, M. L.; Nordin, M.; Dutoit, G.; Pol, L. R. \& Waldburger, M. Low back pain in schoolchildren. A study of familial and psychological factors. Spine (Phila Pa 1976), 20(11):1265-70, 1995.

Balagué, F.; Dutoit, G. \& Waldburger, M. Low back pain in school children. An epidemiological study. Scand. J. Rehab. Med., 20(4):175-9, 1999.

Bjelica, D.; Popovic, S.; Kezunovic, M.; Petkovic, J.; Jurak, G. \& Grasgruber, P. Body height and its estimation utilizing arm span measurements in Montenegrin adults. Anthropol. Noteb., 18(2):69-83, 2012.

Bjelica, D; Popovic. S. \& Petkovic, J. Comparison of instep kicking between preferred and non-preferred leg in young football players. Monten. J. Sports Sci. Med., 2(1):5-10, 2013.
Bogduk, N. Clinical Anatomy of the Lumbar Spine and Sacrum. New York, Churchill Livingstone Inc., 2005.

Gabbett, T. \& Georgieff, B. Physiological and anthropometric characteristics of Australian junior national, state, and novice volleyball players. J. Strength Cond. Res., 21(3):902-8, 2007.

Dejanovic, A. \& Zivkovic, D. Correlation between anthropometric characteristics and body isometric endurance of the lumbar and abdominal musculature children. Phys. Educ. Sports, 6(2):85-93, 2008.

Demura, S. \& Miyaguchi, K. Evaluation of muscle power exerted by explosive gripping. J. Strength Cond. Res., 23(2):465-71, 2009.

Hadzic, R.; Bjelica, D. \& Popovic, S. Comparative study of anthropometric measurement and body composition between elite basketball and volleyball players. Res. Phys. Educ. Sport Health, 1(1):103-8, 2012.

Koley, S.; Khajuria, A. \& Melton, S. The correlation between power and leg strength back in Indian cricket players from different universities. Phys. Educ. Sports, 8(2):125-32, 2010.

Mannion, A. F.; Adams, M. A.; Cooper, R. G. \& Dolan, P. Prediction of maximal back muscle strength from indices of body mass and fat-free body mass. Rheumatology (Oxford), 38(7):652-5, 1999.

Maffulli, N. The growing child in sport. Br. Med. Bull., 48(3):5618, 1992.

McGill, S. M.; Childs, A. \& Liebenson, C. Endurance times for low back stabilization exercises: clinical targets for testing and training from a normal database. Arch. Phys. Med. Rehabil., 80(8):941-4, 1999.

Micoogullari, B. O.; Kirazci, S. \& Altunsöz, S. Effects of internal, external and preference of attentional focus feedback instructions on learning soccer "head kick". Monten. J. Sports Sci. Med., 1(1):21-6, 2012.

Mladenovic-Ciric, I. \& Duraskovic, R. Analysis of morphological characteristics and functional abilities of girls selected for volleyball. J. Anthropol. Soc. Serb., 43:207-11, 2008.

Melrose, D. R.; Spaniol, F. J.; Bohling, M. \& Bonnette, R. A. Physiological and performance characteristics of adolescent club volleyball players. J. Strength Cond. Res., 21(2):481-6, 2007.

Nejic, D.; Stankovic, R. \& Joksimovic, A. Differences in motor abilities in volleyball and football players. J. Anthropol. Soc. Serb., 44:191-9, 2009.

Noyes, F. R.; Barber-Westin, S. D.; Smith, S. T. \& Campbell, T. A training program to improve neuromuscular indices in female high school volleyball players. J. Strength Cond Res., 25(8):2151-60, 2011. 
BOGDANOVIC, Z.; SMAJIC, M.; JAKSIC, D.; MILOSEVIC, Z.; OBRADOVIC, B.; GOGIC, A.; VIDAKOVIC, H. M.; LJUBISAVLJEVIC, M.; DRASKOVIC, V.; VISNJIC, S.; MEKIC, H.; STANKOVIC, R.; IVANCIC, G. \& POPOVIC, S. Lumbar and abdominal muscles isometric potential in volleyball cadets. Int. J. Morphol., 32(3):1036-1042, 2014

Nikolaidis, P. T.; Ziv, G.; Arnon, M. \& Lidor, R. Physical characteristics and physiological attributes of female volleyball players--the need for individual data. J. Strength Cond. Res., 26(9):2547-57, 2012.

Parizkova, J. Human growth, physical fitness and nutrition under various environmental conditions. In: Shephard, R. J. \& Parizkova, J. (Eds.). Human Growth, Physical Fitness and Nutrition. Basel, Medicine and Sport Science, 1991.

Popovic, S.; Bjelica, D.; Molnar, S.; Jaksic, D. \& Akpinar, S. Body height and its estimation utilizing arm span measurements in serbian adults. Int. J. Morphol., 31(1):271-9, 2013a.

Popovic, S.; Akpinar, S.; Jaksic, D.; Matic, R. \& Bjelica, D. Comparative study of anthropometric measurement and body composition between elite soccer and basketball players. Int J. Morphol., 31(2):461-7, 2013b.

Salminen, J. J.; Oksanen, A.; Mäki, P.; Pentti, J. \& Kujala, U. M. Leisure time physical activity in the young. Correlation with low-back pain, spinal mobility and trunk muscle strength in 15-year-old school children. Int. J. Sports Med., 14(7):406$10,1993$.

Stojanovic, T.; Nesic, G. \& Karalic, T. Comparative analysis of motor models volleyball pioneer selection of Serbia in the period since 1996 to 2004 year. J. Anthropol. Soc. Serb., 43:229-37, 2008.

Stojanovic, T.; Nikolic, M.; Duraskovic, R. \& Milkic, D. Comparative analysis of some anthropometric measures and motor abilities of young male and female volleyball players. J. Anthropol. Soc. Serb., 40:249-54, 2005.

Stojiljkovic, S. Fundamentals of general motor skills. Nis, Student Cultural Center, 2003.

Viry, P.; Creveuil, C. \& Marcelli, C. Nonspecific back pain in children. A search for associated factors in 14-year-old schoolchildren. Rev. Rhum. Engl. Ed., 66(7-9):381-8, 1999.

Watson, K. D.; Papageorgiou, A. C.; Jones, G. T.; Taylor, S.; Symmons, D. P.; Silman, A. J. \& Macfarlane, G. J. Low back pain in schoolchildren: occurrence and characteristics. Pain, 97(1-2):87-92, 2002.

Weiner, J. S. \& Lourie, J. A. Human Biology. A Guide to Field Methods. IBP Handbook N 9. Philadephia, Davis Company, 1969.

Zivkovic, D. \& Dejanovic, A. Prediction of the isometric endurance of the lumbar and abdominal musculature of young boys. Phys. Educ. Sports, 6(2):95-104, 2008.

\section{Correspondence to: \\ Stevo Popovic \\ Faculty for Sport and Physical Education \\ University of Montenegro \\ Narodne omladine bb, 81400 Niksic \\ MONTENEGRO}

Tel : $00382(40) 235207$

Fax: $00382(40) 235200$

Email: stevop@ac.me

Received: 12-10-2013

Accepted: 15-05-2014 